\title{
An Overview of the Development of University Library in the Information Age
}

\author{
Shanshan Shang, Yiming Mi, Luyan Yang*, Kun Jiao, Fang Sheng, Yuanrui Shen, Hua Guo \\ Library, Shanghai University of Engineering Science, Shanghai, China \\ Email: *516096696@qq.com
}

How to cite this paper: Shang, S.S., Mi, Y.M., Yang, L.Y., Jiao, K., Sheng, F., Shen, Y.R. and Guo, H. (2017) An Overview of the Development of University Library in the Information Age. Open Journal of Social Sciences, 5, 1-10.

https://doi.org/10.4236/jss.2017.511001

Received: September 12, 2017

Accepted: October 29, 2017

Published: November 1, 2017

Copyright $\odot 2017$ by authors and Scientific Research Publishing Inc. This work is licensed under the Creative Commons Attribution International License (CC BY 4.0).

http://creativecommons.org/licenses/by/4.0/

\begin{abstract}
With the advent of the information age, the university library reader service work has gradually developed toward informatization, networking and facilitation. In a certain extent, the service level of libraries can be improved by the study of libraries' development rules and trends in a scientific way. The study mainly analyzes the current situation of the development of university libraries in China. The University Library in the new era is bound to be a complex library of traditional libraries, digital libraries and mobile libraries. It will be the development direction of university library in the future to pay equal attention to high-tech hardware equipment and high quality extension service without losing its own characteristics.
\end{abstract}

\section{Keywords}

University Library, Information Age, Reader Service, Service Innovation

\section{Introduction}

Library is a collection of human wisdom, with nearly 5000 years of development history. According to records, Egypt has a library as early as 3000 years ago. The library, as an important carrier of knowledge and culture, has made outstanding contributions to the development of mankind [1]. With the rapid development of cloud computing technology, large data storage technology, wireless communication technology and sensor network technology, the function and effect of library have also undergone reforms radically. The library can accurately identifies and senses the reader's service needs, reading behavior, social relations, service methods and business models through the use of large data resources, to clarify the characteristics of competitive service environment, carry out accurate personalized service and improve their own quality of service, so that readers get 
rid of reading time, geographical, service objects, reading content and the type of terminal constraints.

The educational function of the library is also showing its great potential, and many countries have realized the role of the library education function in the social and economic development. And the university library is the forefront of national education positions, directly facing the higher talents of the motherland; it should become a demonstration area of human culture inheritance and innovation [2]. As far as the cultural construction of colleges and universities is concerned, the key lies in university library. University library, an indispensable and important role in the construction of advanced culture in China, is the basic facilities for the inheritance and innovation of human culture. The amount of library documents, the level of service and the quality of technical equipment have become important standards to measure the level of teaching and research in a university. Famous universities at home and abroad, the reason why talented people, fruitful, well-known, in addition to the high level of teachers and advanced laboratory equipment, the library makes a crucial contribution. Guo Moruo, a famous Chinese scholar, once said that there is no first-class library, there is no first-class university.

University library is responsible for the teaching, research, administration and other functions in the university, plays an important role in the development of higher education. The construction of library management personnel and the collection construction should be strengthened, giving full play to the advantages of libraries, doing well the work of reading and moral education, circulation reading guidance and propaganda and guidance for college students, make the service function of university library play a greater role in the development of colleges and universities. Therefore, the new era of university library based on the traditional library, should speed up the construction of the hybrid library, improve extension services, share resource, strengthen cooperation, set up special libraries and make constant innovations, to serve the college students and the whole society more effectively.

\section{2. "Trinity System": Speed up the Construction of Compound Library}

The continuous development of a series of IT technologies, such as computer technology, Internet and multimedia communication technology and high-speed broadband network information transmission technology, makes the e-library more inclined to diversification, electronization and digitization of the knowledge carrier in the library collection. The emergence of electronic publications on network databases, CDs, disks and other non-prints has enabled the development of electronic libraries with a technical and material basis. The electronic development of the library will promote the second deepening of the development of library industry in China. However, the development of electronic reading room and network database can also be regarded as a useful attempt to develop electronic library in recent years. 
The digital library of the new era refers to the digital resource library group which is connected through the internet, a computer system which carries out distributed management information and knowledge sharing, which is as multimedia digital resources, cross-platform and cross-language network access, computer system distributed management and intelligent services the main features, to mainly achieve the sharing of information and knowledge resources.

The construction of digital library is more necessary and urgent as a result of the late research and development of digital library in our country. In 1995, the National Library of China (formerly Beijing Library) began to track the development of international digital library, absorbed the most advanced technological achievements in the contemporary, combined with the actual situation in China and repeatedly organized experts to demonstrate repeated [3]. After that, the State Planning Commission approved the 'China Experimental Digital Library' project in 1997 by the Beijing Library, Shanghai Library, Nanjing Library, Guangdong Zhongshan Library, Shenzhen Library and Liaoning Library. The National Library in July 1998 formally implemented the "China Digital Library Project" on this basis, was launched in Beijing on April 18, 2000. And Beijing held a seminar on "Digital Library and China" on May 23, 2002. China Digital Library Project has entered a substantive stage of operation. In October 1998, Li Lanqing, vice premier of the State Council, inspected the National Library, pointed out that "the future of the library model, is the digital library", therefore, the construction of digital library in colleges and universities began to flourish in China, and the university library should play a model and take the leading role in it, to maximize the advantages of digital libraries.

On the basis of the popularization and optimization of digital library application, the construction of mobile library should also be started for some competent university libraries. Mobile library provides users with a strong information resources services by using the Internet and the user's laptop and mobile phone as an information receiving platform. It uses the civilianization of the smart mobile device such as smartphones, tablets, e-readers, as well as the coverage and development of $3 \mathrm{G}$ networks to make readers can enjoy the library diversification service anytime and anywhere, and no longer limited to the existence of physical libraries. The college students are the groups who use the library at the highest frequency, also are the easiest to accept new technology products, so the development of university mobile library for China's higher education has a positive significance.

The construction and development of mobile library can not only improve the quality and efficiency of library service, but also make the reader have higher autonomy and arbitrariness in obtaining library information and service. The initial design concept of the mobile library is to facilitate the use of library resources by readers in remote areas to meet the needs of readers. The innovation of mobile Internet is the mobility, whose connotations are real-time, privacy, portability, and accuracy, and it's different from the Internet's innovation. The 
value of mobile Internet is the social information of the Internet and mobility, which is also the dual driving force of the development of social informatization.

The third generation of communications technology revolution swept the whole world, Japan took the lead in the opening of the $3 \mathrm{G}$ services, in the beginning of this century to the three leading communications companies are issued a network license. Subsequently, Japan has extensively experimented with the application of $3 \mathrm{G}$ technology in various fields. Japan is also the first to apply $3 \mathrm{G}$ technology to the library, such as bibliographic retrieval system, which can use mobile phone to surf the Internet, researched by the Toyama University, University of Tokyo launched an online directory query service, the user can achieve bibliographic retrieval and borrowing through the Internet, but also send reminders, booking reminders, renewing books and other SMS notification service to the reader; South Korea has also launched a library mobile services, readers can also use the phone for bibliographic retrieval, browsing, make an online booking without going to the library. At present, China's smart phone users have reached about 500 million, which has provided the necessary basis for the construction of mobile libraries, the need for a complete mobile library in daily demand is also increasingly prominent.

In recent years, the construction of mobile libraries in China has also achieved fruitful results. Beijing Institute of Technology opened the "Library Short Message Service System" on December 3, 2003, which became the first university library that uses mobile phone messages to remind back books in China. Shanghai Library launched a mobile library services in 2005, which is the domestic earliest practitioners of mobile phone service, has been achieved 24-hours self-help library in 2010. China National Library opened the "pocket national library" service on December 22, 2008, which provides online lectures, online exhibitions, online reading, books recommended, lecture notice and other services for readers in time, Since then, domestic libraries have mushroomed to develop mobile library applications, and now most libraries have been achieved WAP service model.

In the present and future period, the modern compound library will be the trinity library of the traditional library, the digital library and the mobile library. The compound library in the information era is that the organic combination of the traditional library, the digital library and the mobile library which is of coexistence and complementarity in the complex environment where the printed literature and the electronic literature or the virtual literature are coexisting. The traditional service and the emerging mobile information service will co-existence in more libraries, the two services can complement and facilitate with each other and form a complete system of online and offline service modes which not only conform to the trend of the development of the times, but also meet the reader's wishes. As an ordinary reader, not only can we accept the information service of the library face to face, but also can feel the convenient and quick mobile information service through the wireless access technology. 


\section{Service Extension: Clear Function Positioning}

The extended service is, out of the library wall, the one which university library provides for the teachers and students. As early as the 1960s, American scholars Westbrook and Waladaman defined extended services as library services other than the core business of reference services. We have limited the library extension service to the expanded service which public libraries develop on the basis of the original service to attract more users all the time. Compared with the public library, the consciousness of extended service in many university libraries is lagging behind.

The innovation of American university library extension service is of great reference significance for our university library to carry out extended service better. At present the content of American university library extension service is not limited to a single service, but a diversified situation. The main services are: reference services (on-site reference and specialized counseling services for teachers and students), academic research services (semester paper support and compilation of teaching materials), skills training services (freshman training and information literacy education), and other services (a variety of lectures, seminars, library visits and so on). University library in our country can carry out the characteristics service aiming at the characteristics of college students in China through learning from the extended service of American university library.

When carrying out the extended service, the university library should arrange the time and space reasonably, adopt a flexible and diversified way of propagan$\mathrm{da}$, and cooperate with the relevant departments of the university actively on the basis of expanding the content of the service. In the information age, there are many factors that restrict the sustainable development of the library. The correct function orientation is the guiding ideology of sustainable development of the library, and all-round business innovation is the driving force of sustainable development of the library, the way and the guarantee of sustainable development of library is people-oriented and scientific management, respectively. Effective co-construction and sharing is the fundamental way out for the sustainable development of the library.

While upgrading the hardware facilities, the libraries work are still the service first, people-oriented. Among them, librarians and readers make up two large divisions of libraries. We should be people-oriented, strengthen the management of librarians and readers, fully mobilize the enthusiasm of people and stimulate people's awareness of innovation to develop the value-added information. And we should not only strengthen the people-oriented management and the management of librarians, introduce the competition mechanism, strengthen to cultivate and create high-quality comprehensive talents with innovative sense, but also strengthen the library's cultural construction and improve the ideological quality of librarians. To implement talent incentive management, the development of and rational use talent are essential to the survival of the library; To 
strengthen the reader management, to be the reader service-oriented, transfer from literature to knowledge, from librarian service to reader self-service. Only in this way can libraries develop rapidly.

In order to meet the needs of information society development and information exchange process, the library should change the operation mechanism of traditional reference service, expand the functions and scale of library information consultation service to form its own business scope, content, organization and cadre team, And modern information processing technology should be widely used to develop more new work. Such as the implementation of resource sharing on the basis of the establishment of the website, which provides users with the subject search easily: a phone, an online fax. Library's knowledge service function is a solution-oriented service, which focus is no longer simply providing the information needed to the user, but solving the user's actual problems through the service. To solve the practical problems of users often experience the deep development of information resources, such as melting and reorganization information, so library service in the information age is a forward-looking information research activities.

\section{Resource Sharing: Enhance Communication and Cooperation between Institutions}

In the past, the backwardness of library business is one of the important reasons for restricting the development of library. Document information with manual service is incomparable with modern means of service. The library automation management system can achieve the automatic management of purchasing, cataloging and circulation. The reader can quickly find the storage and borrowing of the books and materials needed by the computer. At the same time, the staff can greatly improve the work efficiency. Collection of books and periodicals can be a single input and multiple output, and the format of the catalog is neat and standardized. On the one hand, library automation management solve the contradictions between hard-to-get literatures' supply and demand and the problem of overdue fines to make the circulation work is more humane by online booking, reminder, recommending new books and other business. On the other hand, the establishment of libraries' information network can configure the literature resources reasonably, do online collaboration interviews, centralized cataloging and interlibrary, work statistics which management required have become very convenient. Compared with the traditional manual operation, the use of information technology promotes and improves the management of the library.

Libraries provide personalized service through the establishment of the reader information database, the use of relevant software to track the reader's knowledge and information needs, the analysis and research of learning knowledge direction and characteristics. For example, we can calculate the reader's reading rate to reflect the demand for information from readers over the past year and draw the annual trend graph of readers' information needs by calculating the 
monthly reading rate. The reader's learning or research direction and the trend of demand for certain information can be also reflected by calculating the rate readers get information.

There is the way to achieve lower costs, interoperability, complementary advantages, user-friendly, effective value-added fast way for the library is collaborative procurement and resource sharing, it is also the fundamental way to achieve sustainable development. The arrival of the information age provides a technical guarantee to achieve the real sharing of literature resources. The library's fragmented situation can be changed by strengthening the role of government's macro-guidance, planning, incentives and regulation, legislating and implementing relevant policies to achieve resource sharing. Shared objects include library and information community, various online information retrieval systems, networks, and so on. The effective means of sharing resources are: joint procurement, division of labor collection, preservation sharing, cooperation cataloging, document delivery, mutual borrowing. The best mode of the information resource sharing is the document information security system which basis on modern communication technology and the standardization principle.

Data collection of readers' reading service is the main research data in the university libraries. The data include: reading demand information which feedback by readers, the readers' query and search history of the library website content and the users' selection and deletion of service content and other behavioral data. Collection of relevant information about reading activities, include readers' individual characteristics data, reading habits, types and modes of reading purpose and so on. Reading content and selection of service model mainly concerns the pattern of Library users' service, methods and contents of user services, types and ways of reading application, ways selection and trends of reading activities and other data. Website access logs, reading contents' search and download, the server's reading of reading behavior, the frequency of reading, the total online time of the reader, the search and browsing of the reading content, the classification of the reading content, the reading of social relations and friends interaction, the location information of the mobile reading terminal and the read-related behavior on the third-party website constitute the reading activity. The reading feedback behavior is mainly evaluated by readers' reading experience and user satisfaction. Library website is the most convenient access to academic resources for researchers, so American first-class university library homepage is focused on providing comprehensive and efficient scientific research services for academic staff in the construction process. Such information need to be exchanged between the university libraries, so as to realize the sharing of resources in real sense.

University libraries should also enhance the cooperation with local public libraries, joint procurement must develop a unified procurement standards which comply with the museum's collection characteristics and development model because of the different service object and the different focus of the construction of the literature resources. Compared with the universal service of the public 
library, the university library is characterized by professional and systematic, while the public library collects documents as comprehensive and timely as possible. And the purchasing standards of the two sides complement each other and do not conflict with each other. University library can carry out social services on the basis of protecting teachers and students' literature needs, divide social users into the industry, so that they participate in the literature recommended activities to make the targeted literature procurement. Public library collection standards pursue for the "big and the whole", "small and fine" principle, after the implementation of collaborative procurement, the public library focused on the construction of local literature, to avoid duplication of construction, which can not only save money, but also enhance the guarantee of collection of literature. Therefore, every library creates a different collection style according to its own collection characteristics and development direction. University library is committed to the professional, systematic academic collection systems, extended to the region's social industry crowd. While collecting resources in a timely and comprehensive way, the public library focused on the construction of local literature resources.

When the library service is more socialized, the public benefit in the dissemination of knowledge, information exchange, culture and entertainment, as well as physical and mental health, the concept, society cannot do without the library, and supporting the development of the library consciously, will get social acceptance. For example, the Guangdong library has carried out various forms of information service around the economic construction, which has been greatly welcomed by the users and vigorously supported by the government and the whole society.

\section{Building a Characteristic Library: Stand out in the Information Age}

In the information age, the university library must correctly understand itself, carefully analyze the environment, know ourselves and the enemy, avoid weaknesses, formulate the scientific development strategy, enhance the construction in various capital elements, create and maintain their own competitive advantage, and thus do targeted construction to create a new situation in the development of the library. Therefore, the library services will also be targeted at their own characteristics of colleges and universities to tend to provide more personalized service.

Excellent hardware equipment and high quality services are not enough for the University Libraries at this stage. So many university libraries have turned their attention to the construction of characteristic libraries. According to the survey, 66 colleges and universities in Shanghai have 88 characteristic databases, accounting for $32 \%$ of the total in 2013 . One of the highlights is the collection features, and some university libraries abroad are known for their special collections, such as the University of Cambridge Library and the Yale University Library. The collection features of some university libraries in our country are 
quite large, and it is an important task for them to digitize this part of resources and build characteristic databases. Such as "ancient book retrieval system" and "Journal of the Republic of China" in Fudan University, 'full text e-book library' and 'Chinese genealogy database' in East China Normal University and so on.

However, the characteristics construction of universities library do not mean that the government does not need to carry out unified planning and regulatory deficiencies. Local provinces and municipalities need to set up a special group to organize and coordinate, implement in the form of project establishment to make a number of colleges and universities build cooperation and division of labor. The University Libraries involved in the construction shall declare their respective special projects and manage them in accordance with sub project after approval of the project, and receive some funds from the research group, and other funds should be raised by themselves. The project adopts the model of centralized management, unified platform and standard, dispersed database construction, centralized service, resource sharing. The research group is responsible for supervision, guidance and evaluation of the sub projects. The co-ordination and coordinated development of the characteristics of the database, can not only avoid duplication of construction, fill the vacancy, but also communicate and complement each other, and build characteristic database jointly, to achieve the rational allocation and optimize integration of characteristic resources.

Doing research and demonstration work well is also essential to a preparatory work, the relevant departments should strictly selected topics. The construction of the characteristic database is a complicated and arduous project. Before the construction of the database, we must go through extensive and in-depth research and careful demonstration to ensure the feasibility of the database construction, focusing on the pre-built database owned or expected to have, such as resource richness, the systematic content, the degree of completeness, the required development cycle, as well as digital processing technology level and ability, funding security, digital construction experience of talent team, information technology level and ability.

In addition, standardization is an important guarantee for high-quality database, but also the premise and basis for achieving resource sharing. The construction standards of characteristic libraries should be in line with the current standards, such as a series of relevant standards in "China's digital library standard construction" project, metadata index format specification, the relevant literature recorded standards in international and national. Besides, some norms need to be developed, such as Information resource heterogeneous integration retrieval specification; specification of information resource processing; thematic document metadata specification; thematic digital object specification; and thematic literature database description rules, which ensure readers can retrieve the required information accurately, completely and quickly, and achieve the systems' subsequent development and functional expansion. 


\section{Conclusions}

University library business is not only related to the overall situation and future development of the school, but also closely related to the cultivation and education of students. Therefore, the library construction must be one of the priorities of the university. The way of libraries' development is the use of emerging technologies, hardware and services equally in the information age. Only by exerting its own advantages, building and revitalizing a characteristic library, can we stand out in the tide of the new era.

In the information age, the university library should change the traditional management mode effectively, try to open up a new situation of library construction, form a noble and excellent library culture, serve for the campus culture construction, affect teacher and student with a stronger spiritual power, strengthen the cohesion of colleges and universities, improve the quality of campus culture, to ensure the coordinated development of the material and spiritual civilization.

\section{References}

[1] Xu, T. (2014) Trend and Development of Reader Service Work of Library in the Information Age. Office Business, No. 9, 131.

[2] Fang, J.P. (2003) Digitization Is the Development Direction of Library in the Information Age. Library and Information, No. 1, 68-69.

[3] Chen, Y.L. (2008) The Development Trend of the Library. Journal of Changsha Railway Institute: Social Science Edition, 9, 276-277. 